\title{
Article \\ A Full Digital Workflow to Design and Mill a Splint for a Patient with Temporomandibular Joint Disorder
}

\author{
Alessandro Nota ${ }^{1} \mathbb{D}$, Alexander N. Ryakhovsky ${ }^{2}$, Floriana Bosco ${ }^{1, *(\mathbb{D})}$ and Simona Tecco ${ }^{1} \mathbb{D}$ \\ 1 Dental School, Vita-Salute San Raffaele University and IRCCS San Raffaele Hospital, 20132 Milan, Italy; \\ nota.alessandro@hsr.it (A.N.); tecco.simona@hsr.it (S.T.) \\ 2 Department of Prosthetic Dentistry, Central Research Institute of Dental and Maxillofacial Surgery, \\ 103132 Moscow, Russia; a.ryakhovsky@gmail.com \\ * Correspondence: boscofloriana@gmail.com
}

check for

updates

Citation: Nota, A.; Ryakhovsky, A.N.; Bosco, F.; Tecco, S. A Full Digital Workflow to Design and Mill a Splint for a Patient with Temporomandibular Joint Disorder. Appl. Sci. 2021, 11, 372 https://doi.org/10.3390/app11010372

Received: 5 November 2020 Accepted: 29 December 2020 Published: 2 January 2021

Publisher's Note: MDPI stays neutral with regard to jurisdictional clai$\mathrm{ms}$ in published maps and institutional affiliations.

Copyright: (C) 2021 by the authors. Licensee MDPI, Basel, Switzerland. This article is an open access article distributed under the terms and conditions of the Creative Commons Attribution (CC BY) license (https:// creativecommons.org/licenses/by/ $4.0 /)$.

\begin{abstract}
In the rehabilitation of a patient with loss of vertical dimension, repositioning of the condyle may be crucial to avoid loading on the retrodiscal area of the temporomandibular joint (TMJ). However, establishing a new position of the condyle within the glenoid cavity is not a simple procedure, and several indications exist in the literature. Digital techniques and 3D visualization using cone beam computed tomography (CBCT) can help. In this clinical case, the procedure for the repositioning of the condyle is described on the basis of the restoration of the normal widths of the intra-articular spaces using a recently introduced software (Avantis3D). After the end of the rehabilitation with the splint, a second examination confirmed the accuracy of the repositioning with this full digital procedure which represents, in selected cases, a useful choice.
\end{abstract}

Keywords: splint; temporomandibular joint disorders; temporomandibular joint; gnathology; occlusal vertical dimension; anterior repositioning splint; removable appliances; digital dentistry

\section{Introduction}

The position of the mandibular condyle in the glenoid fossa is of great practical importance in dentistry, since many researchers consider it to be the main criterion for projecting prosthetics or orthodontic rehabilitations.

There are various opinions upon the correct position of the condyle in the space of the articular fossa: several authors believe that the heads should be centered on the glenoid fossa [1]; others individuate it in a forward position, close to the articular tubercle [2,3]; some other researchers collocate condyles in the distal and upper position during their rehabilitation (reference position) [4]. Finally, some researchers consider that the condyles can be located at any position, which is finally defined by normalization of masticatory muscle tone [5]. Condylar positional changes might also be related to condylar shape alteration; for example, previous studies show that condyles with osteophyte formations are located significantly more antero-inferiorly in the glenoid fossa at interocclusal position than reference position [6].

It is reasonably believed that one of the causes of intra-articular pain is compression of the bilaminar zone caused by uncorrected position of condyles [7], and one of the manifestations of this condition is a radiologically-diagnosed decrease in the upper and posterior width of the joint space. Thus, from a therapeutic point of view, if joint space is increased, allowing smoother condylar translation beyond the disc surface, irregularities and positional abnormalities disappear [7].

Thus, repositioning of the mandibular condyle can eliminate adverse symptoms caused by compression of the bilaminar zone, such as joint pain and/or noises [6].

The intra-oral splint is an important device to achieve this new condylar/fossa relationship while inducing muscle relaxation [8-10], as it changes occlusal vertical dimension 
in a not-definitive way, thus being a guide for the following prosthetic/orthodontic rehabilitation, representing a mandatory general step of the entire rehabilitative procedure.

In a recent systematic review, Alhaji et al. analyzed the clinical methods to detect mandibular repositioning and a new occlusal vertical dimension, depending on clinical judgment.

This review identified two main streams to determine the occlusal vertical dimension: with the first method, the initial vertical dimension of the natural dentition is transferred to the new dentures mainly by intra-oral measurements, profile tracing, and cephalometric analysis. The other method relies on mandibular rest position, facial aesthetic appearance, swallowing pattern, craniofacial landmarks measurements, cephalometric analysis, phonetics, and existing dentures. The authors underline that all these available techniques have merits and are helpful for routine clinical use. However, they are empirical in nature, controversial, and lack the scientific support. Further, the main conclusion of the review is that no single accurate method exists for occlusal vertical dimension determination.

Their study observed that, in general, all the available clinical techniques have merits and are helpful for routine clinical use, no matter what kind of approach is adapted, but they also have significant limitations that should be considered [11].

Therefore, beyond the clinical procedures, a previsualization of the positions of the condyle - in the habitual intercuspation, and after therapeutic repositioning — certainly allows a more justified and rational choice for the clinician.

Thus, a suitable strategy for carrying out mandibular repositioning remains a visualization of the condyle in the glenoid cavity, which can be obtained with cone beam computed tomography (CBCT), which allows to reliably assess the shape, volume, and position of the condyle head, as well as glenoid fossa [12-17].

In this scenario, mobilizing digital technology and CBCT 3D images could allow the acquisition of crucial details.

Recently, a computer-aided method to project a mandibular repositioning from a CBCT was developed [18]. In the study, the orthodontic models of enrolled subjects are firstly digitized (in .stl format) in maximum intercuspation, after which patients wear standardized splints that are $2 \mathrm{~mm}$ thick (mandibular repositioning) while taking CBCT imaging. On the CBCT, the mandible is virtually "separated" from the rest of the skull, and the .stl files of the dental arches in maximum intercuspation are then matched to the upper and lower jaw. The separated mandibular volume is then registered on the mandibular dentition using the teeth surfaces as a guide. In that way, the clinician obtains two 3D images of condyles: one in habitual occlusion, and the other after mandibular repositioning [18]. That method has the limit that mandibular repositioning is firstly decided clinically, and only subsequently evaluated with CBCT. Therefore, although this method may be considered a valid alternative to clinical repositioning, it is not the best choice.

3D software were recently introduced to assess and modify the position of the condyles, for example by measuring intra-articular space widths (height) by using CBCT images $[16,19]$. These software can also match intra-oral scans with CBCT images, thus allowing to virtually reposition the mandibular condyles based on the width of the intraarticular spaces.

Thus, the aim of the present study is to describe a full digital method to design and CAD/CAM (Computer-Aided Design/Computer-Aided Manufacturing) mill a splint that can achieve the previously-planned condylar position.

This case report allows to verify whether or not the virtually-planned condylar repositioning coincides with the position that was obtained by wearing the occlusal splint designed and milled through this full digital workflow.

\section{Case Report}

An adult female came to our clinic with complaints about the uncomfortable position of the lower jaw, which had been present for some months. The patient complained of 
fatigue of the masticatory muscles, increased tension and pain localized in the preauricular areas, and frequent headaches. Upon examination, no intra-articular noise was present when she opened her mouth. Mouth opening was full, straight, and without deviation or deflection. There were two white lines of skin at the corners of her mouth (classic hyperkeratotic dawn lines). Marked teeth wear on the occlusal surfaces of premolars and lower frontal teeth were observed (Figure 1). Metal-ceramic bridges and crowns were present on the elements 16-14, 26, 27, 35-37, 45-47 (Figure 2), and the dental examination showed that the endodontic therapies and implants present were in good condition.

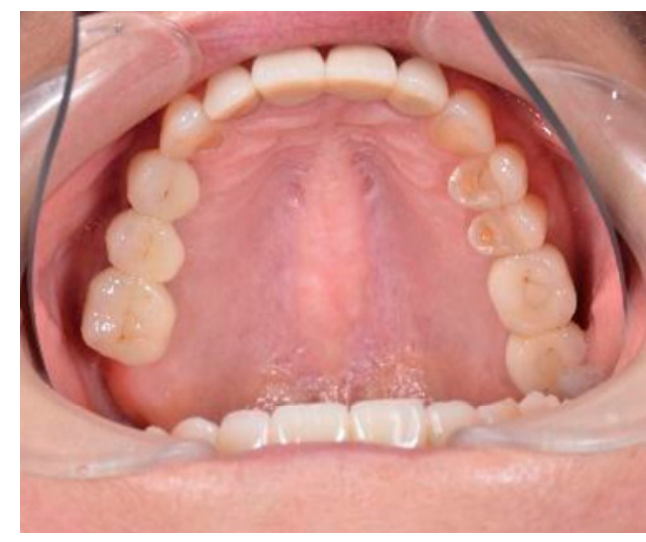

(a)

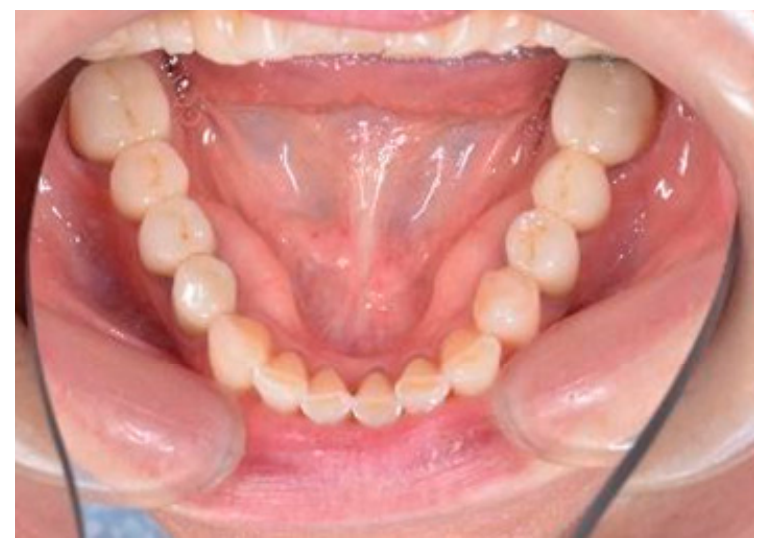

(b)

Figure 1. Marked teeth wear on the occlusal surfaces: (a) upper occlusal view; (b) lower occlusal view.
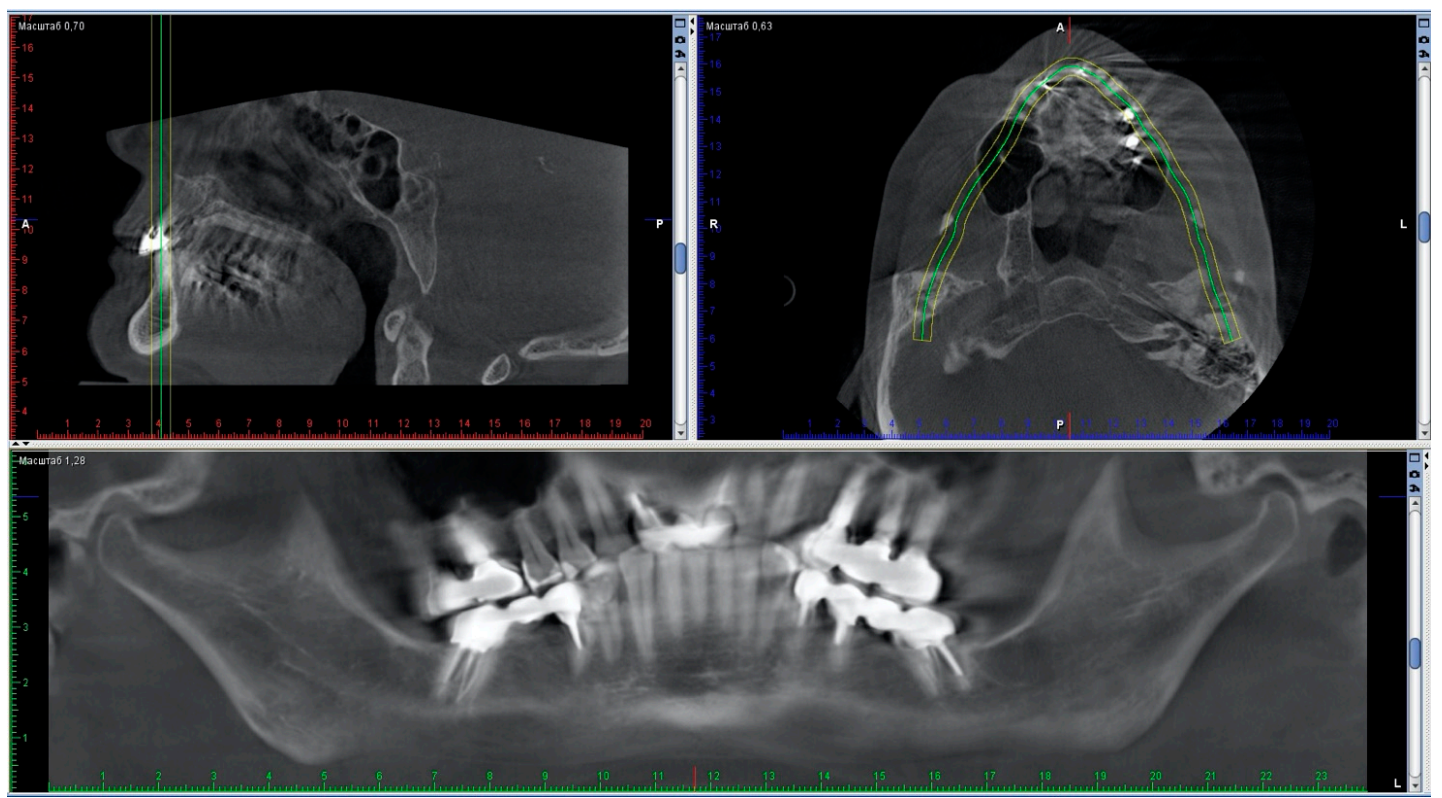

Figure 2. Cone beam computed tomography (CBCT) view of the orthopantomography.

Diagnostic data and physical examination of the patient suggested the need of interocclusal splint treatment with mandibular repositioning, to reduce intra-articular pain. In this clinical case, a full digital workflow was used to design and build the device. The software used was Avantis3D (LLC Avantis3D, Bolshoy Boulevard, 42/1, Off 137/22, Skolkovo. 121205 Moscow, Russia).

Full digital workflow to manufacture the splint was based on the following steps [20]:

1. Import CBCT dicom data of the patient (taken in habitual occlusion), including the dentition and the right and left temporomandibular joints (TMJs) into Avantis3D software. 
2. Matching of .stl files from intra-oral scans of dentition, with CBCT data.

3. Selection of condyles and TMJ fossa from CBCT data (Figure 3).

4. Mesh triangulation, to reproduce surfaces of condyles and articular fossa.

5. Calculation of intra-articular spaces width (in $\mathrm{mm}$ ) (anterior, superior, and posterior spaces) executed by the software (Figure 4).

6. Virtual repositioning of the lower jaw obtained by normalizing intra-articular space width.

7. Virtual design of mandibular repositioning splint on the basis of mandibular repositioning.

8. Milling of the splint.

9. Insertion in the mouth.

10. Follow up.

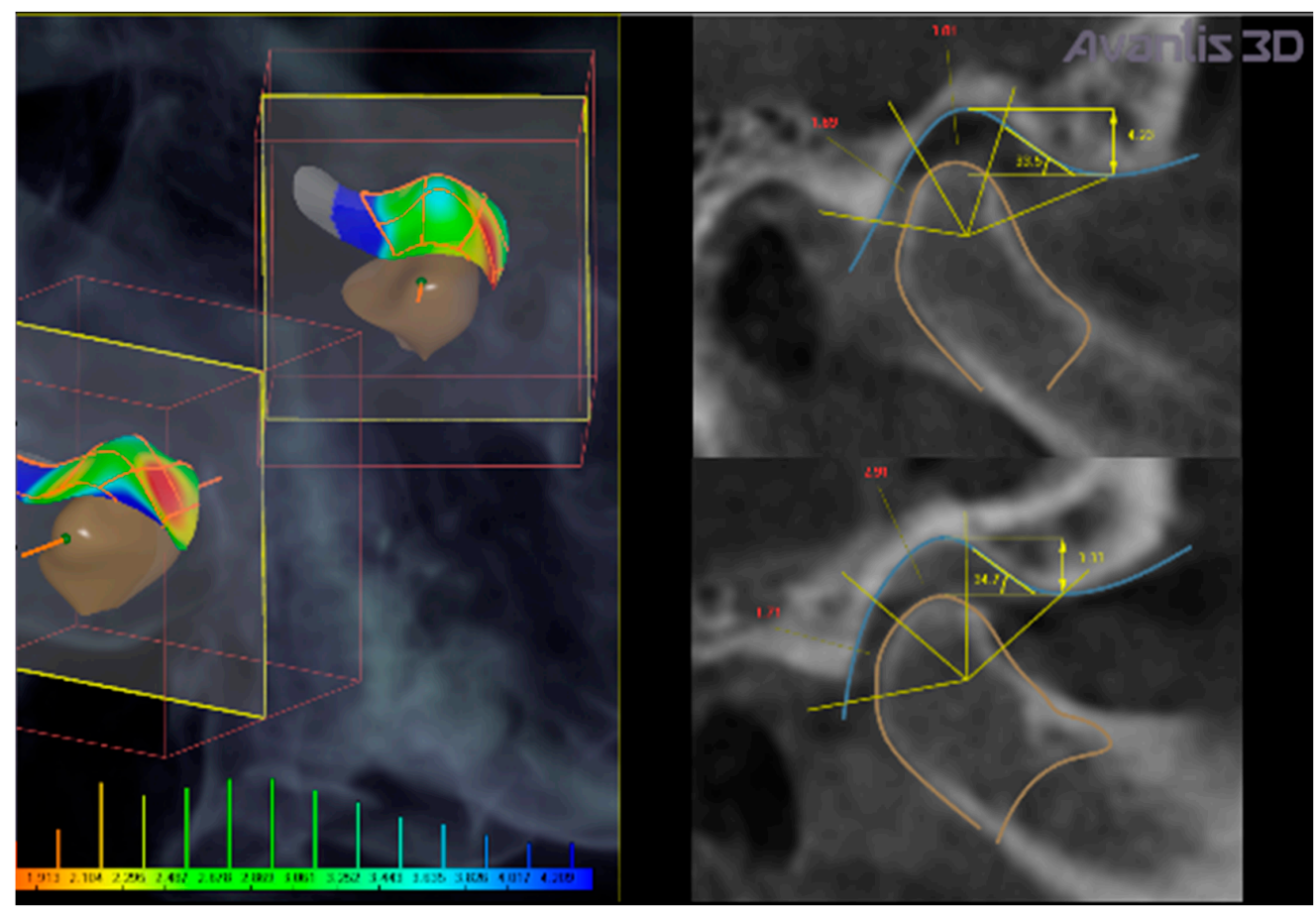

Figure 3. Calculation of intra-articular space widths on CBCT taken in habitual position. Colors evidence reduced (red), normal (green), and increased (blue) intra-articular space widths ranging from 1.9 to $4.2 \mathrm{~mm}$.

\begin{tabular}{|l|c|c|c|}
\hline & $\begin{array}{c}\text { X axis } \\
\text { (Transversal) }\end{array}$ & $\begin{array}{c}\text { Y axis } \\
\text { (Sagittal) }\end{array}$ & $\begin{array}{c}\text { Z axis } \\
\text { (Vertical) }\end{array}$ \\
\hline Left condyle shift & $-0.4 \mathrm{~mm}$ & $0.8 \mathrm{~mm}$ & $0.9 \mathrm{~mm}$ \\
\hline Right condyle shift & $-0.4 \mathrm{~mm}$ & $1.2 \mathrm{~mm}$ & $1.3 \mathrm{~mm}$ \\
\hline Rotation around intercondylar axis & \multicolumn{3}{|c|}{$0.4 \mathrm{deg}$} \\
\hline
\end{tabular}

\begin{tabular}{|l|c|c|c|c|c|c|}
\hline & \multicolumn{3}{|c|}{ Habitual occlusion } & \multicolumn{3}{c|}{ Centric relation } \\
\hline & \multicolumn{3}{|c|}{ Joint space width, $\mathrm{mm}$} & \multicolumn{3}{c|}{ Joint space width, $\mathrm{mm}$} \\
\hline & Anterior space & Superior space & Posterior space & Anterior space & Superior space & Posterior space \\
\hline \multirow{2}{*}{ Left } & $4.32 \pm 1.10$ & $3.01 \pm 0.60$ & $1.69 \pm 0.14$ & $4.06 \pm 0.95$ & $3.70 \pm 0.36$ & $3.00 \pm 0.20$ \\
& $(3.45-7.28)$ & $(1.87-3.57)$ & $(1.53-1.95)$ & $(3.31-6.57)$ & $(3.01-4.15)$ & $(2.80-3.47)$ \\
\hline \multirow{2}{*}{ Right } & $3.59 \pm 0.49$ & $2.91 \pm 0.60$ & $1.71 \pm 0.15$ & $3.93 \pm 0.41$ & $4.07 \pm 0.40$ & $3.38 \pm 0.10$ \\
& $(3.15-4.89)$ & $(1.99-3.69)$ & $(1.52-1.99)$ & $(3.44-4.69)$ & $(3.42-4.61)$ & $(3.27-3.60)$ \\
\hline Norm & $1.70-2.70$ & $3.10-3.90$ & $3.40-4.00$ & $1.70-2.70$ & $3.10-3.90$ & $3.40-4.00$ \\
\hline
\end{tabular}

Figure 4. Table exported by the software. It reports the values of the intra-articular space width, according to CBCT data, before treatment (habitual occlusion, on the left part of the table) and in the virtually-planned new position (on the right part of the table). The entity of condylar repositioning is summarized on the upper part of the table, as condylar shifts and rotation around the intercondylar axis. 
In the present clinical case, CBCT images revealed a narrowing of the posterior intraarticular space width, in respect to normal values established by Rabukhina, that are: 1.7-2.7 $\mathrm{mm}$ for the anterior width; 3.1-3.9 $\mathrm{mm}$ for the superior height; and 3.4-4 $\mathrm{mm}$ for the posterior part) (Figures 3 and 4) [21-23].

The left condyle was repositioned by: $-0.4 \mathrm{~mm}$ in the transversal plane, $0.8 \mathrm{~mm}$ in the sagittal plane, and $0.9 \mathrm{~mm}$ in the vertical direction. The right condyle was repositioned by $0.4 \mathrm{~mm}, 1.2 \mathrm{~mm}$, and $1.3 \mathrm{~mm}$, respectively, in the three planes (Figure 4).

The mandibular repositioning was automatically established by the software through a normalization of intra-articular space widths, and the exact position was visually adjusted by the clinician in the range of normal values.

The software automatically established a virtual repositioning of the lower jaw and obtained normalizing posterior and superior intra-articular spaces.

The new occlusal vertical dimension was then established by lower jaw rotation around a virtual hinge axis passing through the middle points of the condyles (Figure 5 evidences two red points that are the middle points of the condyles).

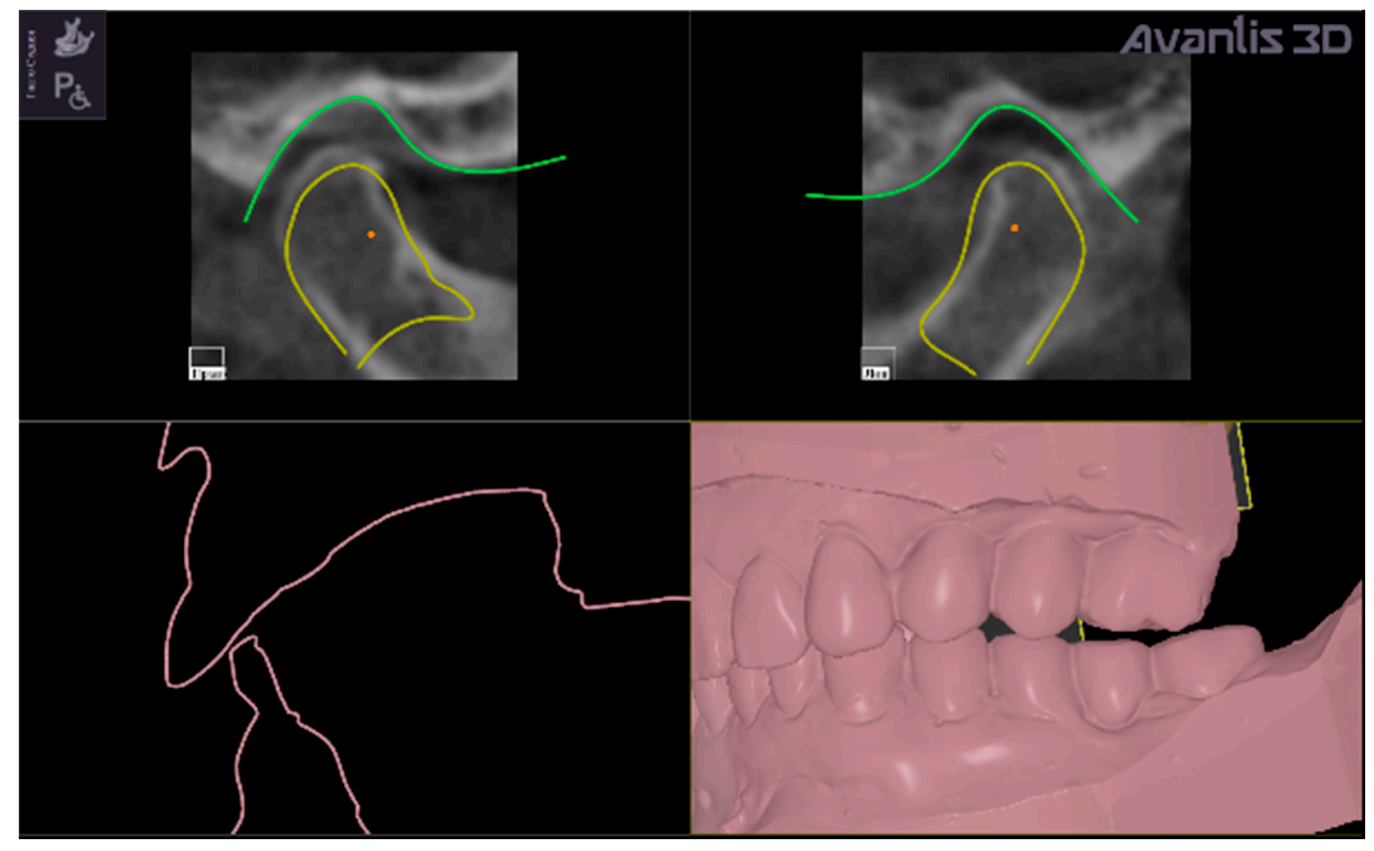

Figure 5. Representation of the virtual shifting of the condyles to normalize the values of the intra-articular space width (yellow contours) and degrees of rotation around intercondylar axis (the virtual hinge axis is the line passing through the red points in condylar heads) to establish the new vertical occlusal dimension (evidenced by pink contour) that is represented as a gap between upper and lower digital models, which will be filled by the virtually designed intra-oral repositioning splint.

The virtual rotation was established at 0.4 degrees (Figure 4 ) to obtain the normalization of superior and posterior space widths.

The middle points of the condyles (represented as red points in Figure 5) are determined automatically by the software on the CBCT 3D reconstruction, connecting the right and left poles of each condyle, thus individuating the middle point of the major condylar axes.

This full digital procedure provides a virtual repositioning of the lower jaw, visually and technically controlled by the clinician, aimed to unload the bilaminar zone in the two TMJs.

The virtual setting of the lower jaw position allowed to obtain a symmetrical repositioning of the two condyles in the glenoid fossa, with the width of the intra-articular spaces never going below the normal range of values. (Figures 4 and 5) 
According to the established new occlusal vertical dimension, a splint was virtually designed with the software, suitably filling the gap between upper and lower dental digital models (Figure 6). It was fixed on the virtual mandible, in contact with the upper teeth (antagonists).

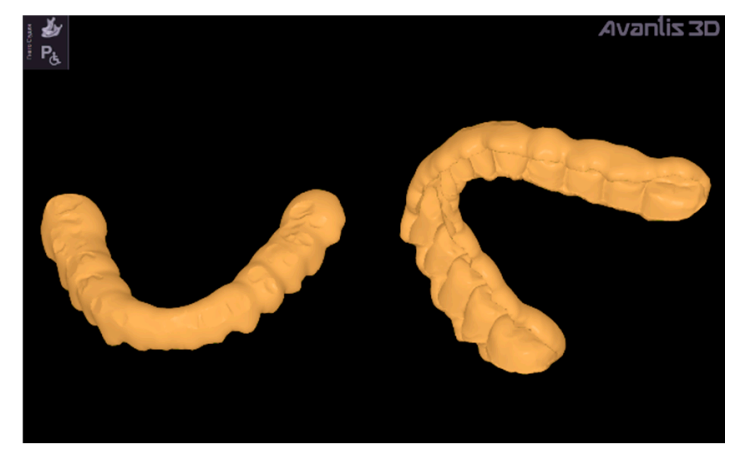

Figure 6. Two views of the virtually designed repositioning splint with Avantis3D software (vestibular and lingual views).

Canine or incisive guidance were not initially modeled on the splint, since the main purpose of such a splint was to set correct and convenient mandibular repositioning in a static position.

A CAD/CAM milling procedure was adopted by using a 5-axis VHF S2 machine (VHF camfacture AG, Ammerbuch, Germany) to manufacture the splint made of transparent polymethylmethacrylate. The milling provided an accurate fit of the splint on the lower teeth without performing any adjustments (Figure 7).
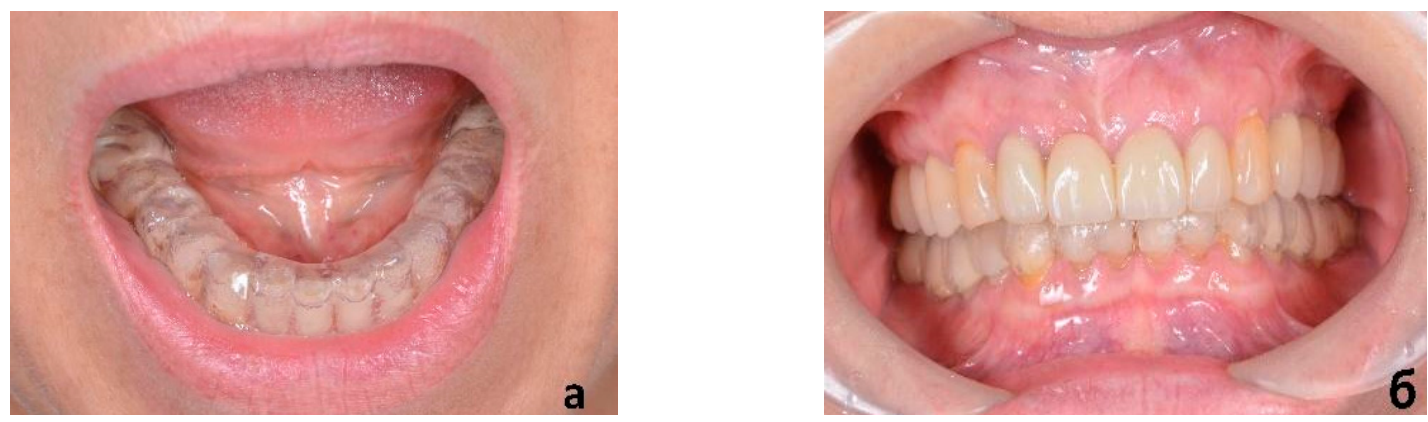

Figure 7. (a) the exact fit of the splint on the lower dentition; (b) when closing the teeth, the upper antagonists corresponds to their prints, guiding the mandible to take the pre-planned repositioning.

After confirming that the splint was comfortable to wear and had sufficient retention, the patient was recommended to wear it at night and during the day as much as possible. An optimal compliance was achievable because the splint design does not significantly interfere with speech and aesthetics.

After three days, the patient came for a checkup, reporting a significant improvement in her symptoms. After she confirmed feeling comfortable in the new mandibular position, functional occlusal adjustments were performed (incisive, canine, or group guidance), analyzing clinically masticatory movements on the splint.

A second CBCT recorded while wearing the splint verified the match between virtuallyplanned and the actually-obtained mandibular positioning. The intra-articular space widths wearing the splint confirmed the achievement of the desired condylar position and the normalization of the values (Figures 8 and 9). These results seem to validate the precision of this full digital workflow. 


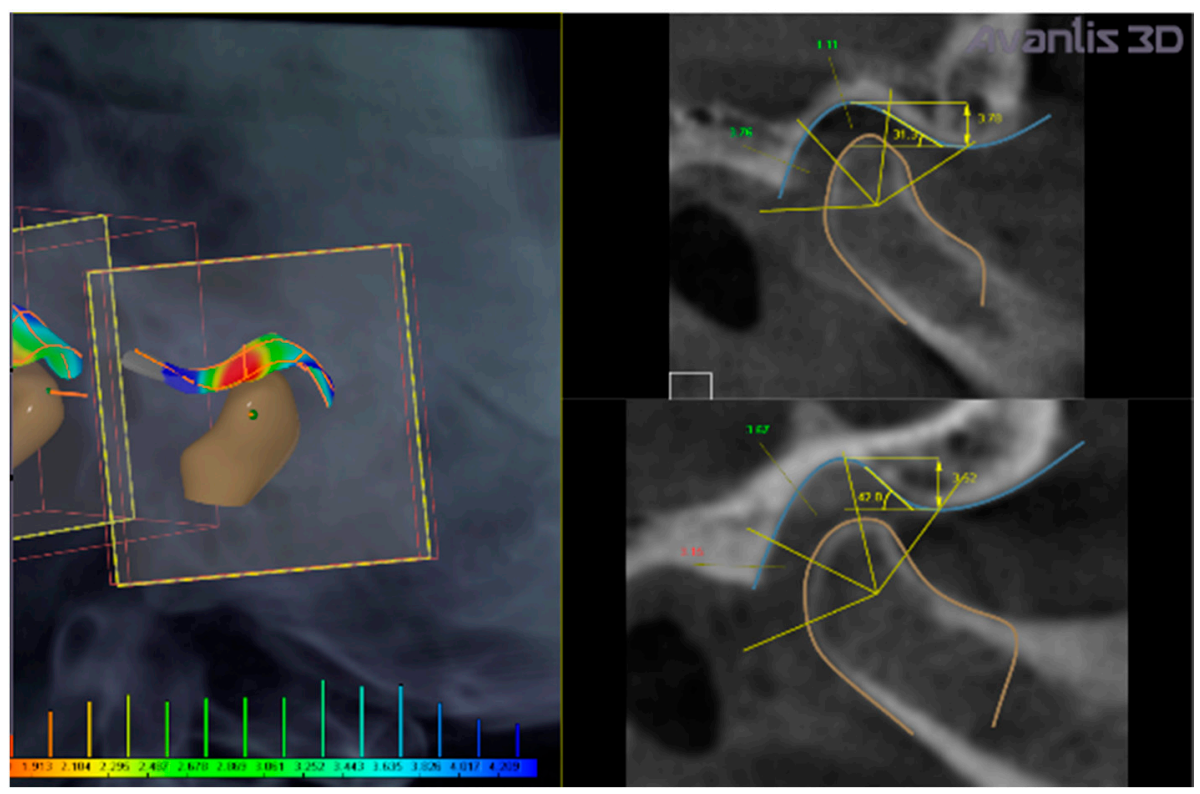

Figure 8. The position of the condyles adjusted by the repositioning splint (observed on the subsequent $\mathrm{CBCT}$ recording with splint). Note that it is very different compared with their position before treatment.

\begin{tabular}{|c|c|c|c|c|c|c|c|}
\hline & \multicolumn{3}{|c|}{ Joint space width, $\mathrm{mm}$} & $\begin{array}{c}\text { Articular } \\
\text { eminence } \\
\text { inclination, deg }\end{array}$ & $\begin{array}{c}\text { Articular } \\
\text { eminence height, } \\
\mathrm{mm}\end{array}$ & $\begin{array}{c}\text { Condyle width, } \\
\mathrm{mm}\end{array}$ & $\begin{array}{c}\text { Condyle } \\
\text { height, }\end{array}$ \\
\hline & Anterior space & Superior space & Posterior space & & & & \\
\hline Left & $\begin{array}{c}2.56 \pm 0.83 \\
(1.12-4.97)\end{array}$ & $\begin{array}{c}3.11 \pm 0.84 \\
(1.21-5.39)\end{array}$ & $\begin{array}{c}4.00 \pm 0.49 \\
(3.38-5.40)\end{array}$ & 31.34 & 3.78 & 19.75 & 11.35 \\
\hline Right & $\begin{array}{c}2.62 \pm 0.66 \\
(1.55-4.54)\end{array}$ & $\begin{array}{c}3.80 \pm 0.56 \\
(2.22-5.04)\end{array}$ & $\begin{array}{c}3.68 \pm 0.47 \\
(2.90-4.59)\end{array}$ & 41.95 & 3.52 & 19.13 & 11.60 \\
\hline Norm & $1.70-2.70$ & $3.10-3.90$ & $3.40-4.00$ & $20.00-50.00$ & $3.50-8.00$ & & \\
\hline
\end{tabular}

Figure 9. Normalization of the values of the intra-articular space widths assessed by the repeated CBCT, taken with a splint in the oral cavity.

The patient was scheduled for a follow-up examination after $4-5$ months, during which the possibility of moving forward with a prosthetic rehabilitation was discussed. In this case, the patient decided not to proceed with the prosthetic rehabilitation right away but to wait, and continued to wear the splint.

\section{Discussion}

In the present case, a full digital workflow was adopted for the patient. Mandibular repositioning was established automatically by the software, which moved the mandible to normalize the intra-articular space widths (Figure 4).

The software was set on the following values of intra-articular space width: for the anterior space in the range of $1.7-2.7 \mathrm{~mm}$, for the superior space in the range of 3.1-3.9 mm, and for the posterior space in the range of $3.4-4.0 \mathrm{~mm}$. Then, the software calculates the intra-articular widths of the clinical case. The intra-articular widths are determined with the software as follows: the most prominent points on the right and left sides of each condyle are individuated on the contours of the horizontal sections of each condyle; then, the most distant points are determined on these contours. Then, segments connect these points, for each condyle, to the glenoid fossa. A total of 45 cross-sections are built along these segments for each condyle. On each section, the distances between condyle and fossa for distal, upper, and medial part are measured (the range of measurements in the present 
clinical case are reported in Figures 4 and 9). The final value is determined as mean and standard deviation of the whole sample of measurements.

The study by Rabukhina (1966) was performed on 300 joints from 150 subjects aged 16 to 35 years (68 men, 82 women) with different types of occlusion: physiological occlusion (orthognathia -60 , straight - 14, progenia-11, biprognathia-5) and abnormal occlusion (progenia -20 , prognathia -18 , deep -12 , macrognathia -2 , micrognathia -3 , partial adentia-3, open-2). The author identified four types of temporomandibular joints, according to the shape of the condyles, to the height of the articular tubercle, to the height and width of the glenoid cavity, to the condyle position in the glenoid fossa, and to the inclination of the back slope of the articular tubercle. That study established that there is no association between the type of joint and the type of occlusion; however, it was determined that type I of TMJ is more common for orthognathic bite, and those data are considered reference physiological values. For that type of joint (called the type I joint), the average size of the anterior part of the gap (anterior articular width) is $2-3 \mathrm{~mm}$, the upper part is 3-4 $\mathrm{mm}$ (upper articular width), and the distal part is $3-5 \mathrm{~mm}$ (posterior articular width).

The Avantis3D software is set on these data, but also allows the clinician to manually adjust the automatically set mandibular position, by moving the corresponding sliders to control the position in the three planes of coordinate system, or by moving the virtual mandible in accordance with the inclination of the articular tubercle slope or in the direction of the articular path. In the present case report, hinge axes were built between medial poles of the condyles, according to Dawson [24], but the software allows the clinician to change the hinge axis position.

After repositioning of the condyle, the parameters of the condyle's paths are automatically determined by the software as well, according to the patented method [20], or set arbitrarily in accordance with the data obtained with an axiography. The achieved mandibular position could be easily reproduced in CAD modeling of prosthetics, or otherwise registered in a traditional way by using silicone pads, which require to be cut into two halves and alternatively inserted on the dentition while recording the bite on the opposite side.

Looking at the $\mathrm{CBCT}$ data, the present clinical case shows a reliable procedure to determine a mandibular repositioning using a full digital virtual modeling, which can be beneficial in the routine clinic. The main advantages of a full digital procedure for mandibular repositioning can be summarized as follows: the possibility of defining a repeatable position of the mandible based on the intra-articular space widths; the possibility of recording the chosen position and saving it for the subsequent prosthetic rehabilitation phase; the possibility of defining the millimeters of the intra-articular space widths; the possibility of designing and milling the splint directly in the dental office; the possibility of reprinting a splint identical to the first one in case of loss, breakage, or wear of the device over time; the possibility of designing additional splints in the same position of the condyles, even after modifications of the occlusal plane due to dental rehabilitation.

This procedure has a limit associated with the fact that $\mathrm{CBCT}$ does not show the anatomy of the TMJ disc, information that can only be inferred indirectly through the evaluation of the joint space widths. Furthermore, the electromyographic activity of the masticatory muscles was not evaluated.

In addition, the functionalization of the splint in protrusion and lateral movements must be adjusted clinically after the delivery of the splint, as the dynamic analyses are not real, but virtually inferred. Clinical studies should be performed in order to confirm the repeatability and efficacy of this procedure.

\section{Conclusions}

An occlusal splint, planned digitally with virtual mandibular repositioning software based on CBCT data, seems to be able to achieve the position that has been established by the operator in subjects with TMD. This method can help establish intra-articular space widths adherent to what is established by the operator, allowing the resolution 
of the symptomatology and facilitating the planning of a potential future permanent rehabilitation.

Author Contributions: Conceptualization: A.N., A.N.R., and S.T.; methodology: A.N.R.; software: A.N.R.; resources: A.N.R.; data curation: A.N., A.N.R., and S.T.; writing-original draft preparation: A.N., A.N.R., F.B., and S.T.; writing-review and editing: A.N., F.B., and S.T.; supervision: A.N.R. and S.T. All authors have read and agreed to the published version of the manuscript.

Funding: This research received no external funding.

Institutional Review Board Statement: Not applicable because the article shows a single clinical case where a standard procedure was applied.

Informed Consent Statement: Informed consent was obtained from all subjects involved in the study.

Conflicts of Interest: A.N.R. is founder and general director of LLC «Avantis3D» and main creator (developer) of Avantis 3D software. All the ideas are implemented in the software by the engineers of «Avantis3D», almost all the instruments of the software were invented and tested by him. A.N., F.B., and S.T. declare no conflicts of interest.

\section{References}

1. Slavicek, R. Relationship between occlusion and temporomandibular disorders: Implications for the gnathologist. Am. J. Orthod. Dentofac. Orthop. 2011, 139, 10-16. [CrossRef] [PubMed]

2. Palaskar, J.N.; Murali, R.; Bansal, S. Centric Relation Definition: A Historical and Contemporary Prosthodontic Perspective. J. Indian Prosthodont. Soc. 2012, 13, 149-154. [CrossRef] [PubMed]

3. Tecco, S.; Tetè, S.; D'Attilio, M.; Perillo, L.; Festa, F. Surface electromyographic patterns of masticatory, neck, and trunk muscles in temporomandibular joint dysfunction patients undergoing anterior repositioning splint therapy. Eur. J. Orthod. 2008, 30, 592-597. [CrossRef] [PubMed]

4. Dawson, P. Evaluation, Diagnosis and Treatment of Occlusal Problem, 2nd ed.; Mosby: St. Louis, MO, USA, 1989.

5. Mccollum, B.B.; Evans, R.L. The gnathological concepts of Charles E. Stuart, Beverly B. McCollum and Harvey Stallard. Georget. Dent. J. 1988, 36, 12-20.

6. Tsuruta, A.; Yamada, K.; Hanada, K.; Hosogai, A.; Kohno, S.; Koyama, J.-I.; Hayashi, T. The relationship between morphological changes of the condyle and condylar position in the glenoid fossa. J. Orofac. Pain 2004, 18, 148-155.

7. Tecco, S.; Caputi, S.; Tetè, S.; Orsini, G.; Festa, F. Intra-articular and Muscle Symptoms and Subjective Relief During TMJ Internal Derangement Treatment with Maxillary Anterior Repositioning Splint or SVED and MORA Splints: A Comparison with Untreated Control Subjects. CRANIO® 2006, 24, 119-129. [CrossRef]

8. Ettlin, D.A.; Mang, H.; Colombo, V.; Palla, S.; Gallo, L. Stereometric assessment of TMJ space variation by occlusal splints. J. Dent. Res. 2008, 87, 877-881. [CrossRef]

9. Baldini, A.; Nota, A.; Cioffi, C.; Ballanti, F.; Cozza, P.; Alberto, B.; Alessandro, N.; Clementina, C.; Fabiana, B.; Paola, C. Infrared Thermographic Analysis of Craniofacial Muscles in Military Pilots Affected by Bruxism. Aerosp. Med. Hum. Perform. 2015, 86, 374-378. [CrossRef]

10. Ciuffolo, F.; Manzoli, L.; Ferritto, A.L.; Tecco, S.; D'Attilio, M.; Festa, F. Surface electromyographic response of the neck muscles to maximal voluntary clenching of the teeth. J. Oral Rehabil. 2005, 32, 79-84. [CrossRef]

11. Alhajj, M.N.; Khalifa, N.; Abduo, J.; Amran, A.G.; Ismail, I.A. Determination of occlusal vertical dimension for complete dentures patients: An updated review. J. Oral Rehabil. 2017, 44, 896-907. [CrossRef]

12. Saccucci, M.; D'Attilio, M.; Rodolfino, D.; Festa, F.; Polimeni, A.; Tecco, S. Condylar volume and condylar area in class I, class II and class III young adult subjects. Head Face Med. 2012, 8. [CrossRef] [PubMed]

13. Nota, A.; Caruso, S.; Ehsani, S.; Baldini, A.; Tecco, S. Three-dimensional volumetric analysis of mandibular condyle changes in growing subjects: A retrospective cross-sectional study. CRANIO® 2018, 38, 320-326. [CrossRef] [PubMed]

14. Saccucci, M.; Polimeni, A.; Festa, F.; Tecco, S. Do skeletal cephalometric characteristics correlate with condylar volume, surface and shape? A 3D analysis. Head Face Med. 2012, 8. [CrossRef] [PubMed]

15. Tecco, S.; Saccucci, M.; Nucera, R.; Polimeni, A.; Pagnoni, M.; Cordasco, G.; Festa, F.; Iannetti, G. Condylar volume and surface in Caucasian young adult subjects. BMC Med. Imaging 2010, 10. [CrossRef]

16. Ryakhovsky, A.; Boytsova, E. 3D analysis of the temporomandibular joint and occlusal relationships based on computer virtual simulation. Stomatologiia 2020, 99, 97-104. [CrossRef]

17. Caruso, S.; Storti, E.; Nota, A.; Ehsani, S.; Gatto, R. Temporomandibular Joint Anatomy Assessed by CBCT Images. BioMed Res. Int. 2017, 2017, 2916953. [CrossRef]

18. El-Beialy, A.R.; El Nigoumi, A.; Kaddah, A.; Afify, H. Using a single cone-beam computed tomography scan to obtain full occlusal details, with the mandible in centric relation and maximum intercuspation. Am. J. Orthod. Dentofac. Orthop. 2018, 153, 741-746. [CrossRef] 
19. Egorova, D.O.; Arsenina, O.I.; Nadtochiy, A.G.; Ryakhovsky, A.N.; Popova, N.V. X-ray assessment of the position of the lower jaw heads in different types of face. Stomatologiia 2020, 99, 55-60. [CrossRef]

20. Ryakhovsky, A.; Ryakhovsky, S.; Vikhodtseva, M. Sposob ispolzovaniya dynamicheskogo virtualnogo artikulyatora dlya immitatsionnogo modelirovaniya okklusii pry vypolnenii proektirovaniya stomatologicheskikh protezov dlya patsienta y nositel informatsii. Patent RU 2652014 C1, 24 April 2018.

21. Shamaeva, G.G.; Rabukhina, N.A. Roentgenological examination of the temporomandibular joint by means of an image intensifier. J. Radiol. Nucl. Med. 1966, 41, 41-44.

22. Rabukhina, N.A. X-ray Department of Central Scientific and Research Institute of Stomatology: Summing up 40-year activities. Stomatologiia 2002, 81, 75-77.

23. Rabukhina, N.A.; Semkin, V.A.; Arzhantsev, N.P.; Lobzin, O.V. Current approaches to the diagnosis and treatment of temporomandibular joint dysfunctions. Stomatologiia 1994, 73, 26-28. [PubMed]

24. Dawson, P. Functional Occlusion: From TMJ to Smile Design; CV Mosby: Maryland Heights, MO, USA, 2007. 